\title{
ALGUMAS REFLEXÕES SOBRE A QUALIFICAÇÃO DO TRABALHO A PARTIR DA SOCIOLOGIA FRANCESA DO PÓS-GUERRA*
}

\author{
Gisela Lobo Baptista Pereira Tartuce ${ }^{* *}$
}

\begin{abstract}
RESUMO: Este artigo procura refletir sobre a pertinência histórica e analítica do conceito de "qualificação do trabalho", em um contexto social que tem demandado a sua substituição pela noção de "competência". Para isso, busca compreendê-lo do ponto de vista teórico, tendo por base o pensamento de Georges Friedmann e Pierre Naville (especialmente o deste último), os pais da sociologia do trabalho na França, no pós-guerra. É nesse país e nesse período que a qualificação começa a adquirir centralidade: ela se torna não apenas um aspecto da prática política e social como, também - e talvez por isso mesmo -, o objeto por excelência da disciplina nascente. Isso significa que a qualificação tem uma história social e interpretativa, e é só por meio dela que se pode decretar ou não o fim de sua vigência analítica. $\mathrm{O}$ texto argumenta que as contribuiçōes de Naville, como precursor da chamada visão "relativista" da qualificação - aquela que a concebe como socialmente construída -, são fundamentais para se pensar o debate "qualificação" versus "competência".
\end{abstract}

Palavras-chave: Qualificação. Competência. França. Georges Friedmann. Pierre Naville.

* Este texto traz alguns resultados de minha dissertação de mestrado $(O$ que há de novo no debate da "qualificação do trabalho"? Reflexōes sobre o conceito com base nas obras de Georges Friedmann e Pierre Naville), na qual analisei teoricamente o conceito de "qualificação do trabalho", tendo por base as obras destes autores, os pais fundadores da sociologia do trabalho na França, na década de 1950. Nessa dissertação fiz um estudo comparativo entre os dois teóricos para saber se, e em que medida, o conceito de "qualificação" de um ou de ambos ainda é pertinente para se pensar a temática na atualidade. Aqui, a comparação é sucinta, e detenho-me mais no pensamento de Naville, porque acredito não só que sua perspectiva possui maior alcance em termos teóricos como também que seu conceito é extremamente atual e mais amplo que a tão divulgada noção de "competência". Agradeço pelos valiosos comentários de Nadya Araújo Guimarães e pelas contribuições dos integrantes de seu grupo de orientação: Sirley Oliveira, Ana Lucia Ferraz, Ana Claudia Cardoso, Rosileide Rosendo e Guilherme Xavier Sobrinho.

** Assistente de pesquisa da Fundação Carlos Chagas e doutoranda do Programa de Pós-Graduação em Sociologia da Universidade de São Paulo (USP). E-mail: gtartuce@fcc.org.br 
Algumas reflexões sobre a qualificação do trabalho a partir...

\title{
REFLECTIONS ON WORK QUALIFICATION FROM THE POST-WAR FRENCH SOCIOLOGY
}

\begin{abstract}
This paper undertakes a reflection on the historical and analytical pertinence of the concept of work qualification, in a social context that has replaced it by the notion of skill. It thus tries to understand it from the theoretical point of view, based on the thought of Georges Friedmann and Pierre Naville (especially that of the latter), the fathers of sociology of work in post-war France. Qualification began to become central in this country and in this period: it became not only an aspect of the political and social practice but also - and maybe for this very reason -, the object par excellence of this arising subject matter. This means that qualification has a social and interpretative history, and only through it may we decree or not the end of its analytical operationality. The text arguments that the contributions of Naville, the precursor of the so-called "relativist" vision of qualification - that which conceives it as socially constructed -, are fundamental to think the debate "qualification" versus "skill".
\end{abstract}

Key words: Qualification. Skill. France. Georges Friedmann. Pierre Naville.

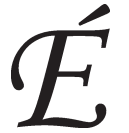

indubitável que a "qualificação do trabalho" ganhou destaque nos últimos tempos. Nos anos de 1980, ela (re)aparece com vigor na Europa, em virtude das transformações tecnológicas, econômicas, políticas e culturais que então atingiam o mundo do trabalho. Concentrado principalmente na França e na Alemanha, o debate girava em torno das possibilidades de uma divisão do trabalho menos acentuada, na qual prevaleceria uma maior/nova qualificação dos indivíduos.

No Brasil, a discussão em torno da qualificação eclode com força nos anos de 1980/1990, quando primeiramente a academia passa a refletir sobre o tema e, em seguida, os sistemas públicos e privados de formação profissional repensam a estrutura e dinâmica de seus cursos. ${ }^{1}$ Mas é no fim da década de 1990, em um forte contexto de flexibilização das relações de trabalho e de desemprego, que a centralidade da qualificação passa para o domínio público: cotidianamente, ela aparece nos discursos do governo, dos empresários, dos sindicatos, da mídia em geral, como instrumento para a solução de problemas individuais - conquista ou manutenção de uma posição no mercado de trabalho - e sociais - aumento de produtividade para as empresas e conseqüente desenvolvimento econômico e social para os países. 
Em contrapartida, se a qualificação tem ganho destaque, ela tem sido simultaneamente questionada pela noção de "competência(s)", que reivindica a si o poder de dar conta das características subjetivas hoje valorizadas e requeridas pelas empresas e pelo mercado de trabalho em geral. Se a penetração e proliferação dessa noção nos mais diversos contextos societais designa novas configurações nas práticas sociais (Ropé \& Tanguy, 1997), torna-se relevante perguntar qual a pertinência da continuidade do uso social e científico do próprio conceito de qualificação: a passagem de um paradigma produtivo a outro requer, necessariamente, a transformação das próprias palavras? Se assim o for, a qualificação pode ser substituída, sem mais, pela competência?

Para responder a essas perguntas, recorro aos pais fundadores da sociologia do trabalho na França, no pós-guerra: Georges Friedmann e Pierre Naville. Essa escolha não é arbitrária: a realidade francesa é, talvez, histórica e analiticamente, aquela que melhor expressa as condições para a construção social e teórica do conceito de "qualificação" e onde, por isso mesmo, os resultados políticos e interpretativos dessa construção ganharam maior relevância; e Friedmann e Naville são não somente os primeiros a refletir sobre o conceito nessa sociedade, mas aqueles que permanecem como forte referência para os estudos atuais sobre o tema, já que foram os precursores, respectivamente, das chamadas visões "substancialista" e "relativista" da qualificação.

Esse retorno à história não significa que a sociedade reproduza ciclicamente as mesmas discussóes sobre os mesmos problemas sem "progredir", mas sim que refletir sobre os desafios e as respostas do passado é uma das maneiras para se compreender o presente, desde que as diferenças deste sejam demarcadas e problematizadas. Assim, ainda que esses autores tenham vivido em um contexto histórico diferente do que hoje se apresenta, acredita-se que suas reflexóes, ancoradas numa ampla tradição empírica associada aos trabalhos teóricos por eles iniciados (Paiva, 1989), são uma contribuição que merece ser recuperada e analisada, pois muitas das discussões que promovemos atualmente já estavam ali presentes, na aurora da automação, ainda que estudos atuais, ignorando as aquisições desses trabalhos anteriores, pareçam redescobrir ingenuamente fatos conhecidos há muito tempo (Dadoy, 1984).

Dessa maneira, procuro mostrar como a construção da qualificação tem uma história, seja do ponto de vista da realidade empírica de 
Algumas reflexões sobre a qualificação do trabalho a partir...

uma dada sociedade, seja do ponto de vista da própria teoria, que, claro, vincula-se aos processos sociais e políticos dessa mesma sociedade. Portanto, a iminente substituição da qualificação pela competência precisa ser precedida de um conhecimento sobre esse processo histórico. Da mesma forma, sua compreensão é necessária para que não se transponha automaticamente para outros contextos um debate que tem sentido na realidade social e no mundo intelectual francês.

\section{A centralidade da qualificação do trabalho na França}

De um modo geral, pode-se dizer que o interesse pela temática da qualificação surge com o aprofundamento da divisão do trabalho no capitalismo, quando a fragmentação de tarefas daí decorrente passa a ser objeto de várias áreas, entre elas a economia - a visão otimista de Adam Smith - e a sociologia - a crítica pessimista de Karl Marx. Entretanto, se esta última ciência nasceu no século XIX refletindo sobre vários aspectos da categoria "trabalho", é apenas no século XX, com o advento da chamada "administração científica do trabalho", que a questão da qualificação vai ser analisada de maneira mais sistemática, tornando-se inclusive o objeto por excelência da sociologia do trabalho na França (Dadoy, 1984).

Essa relevância se deve, em grande parte, ao fato de a qualificação ocupar um lugar central na prática social desse país desde o pós-guerra. De fato, depois da Segunda Guerra Mundial, havia grande reivindicação para limitar as grandes disparidades de salários, provenientes do modo incerto de fixação da remuneração para capacidades de trabalho de natureza diferente ou idêntica. Salários homogêneos para o mesmo tipo de trabalho, como expresso no slogan "para qualificações iguais, salários iguais", tornam-se, assim, a exigência central do movimento sindical, e várias greves foram realizadas nesse sentido. Os trabalhadores ${ }^{2}$ vão se organizar e negociar normas de referência, primeiro no nível da empresa, depois da localidade e finalmente do ramo profissional. Essas normas constituem, pois, tentativas de padronização e objetivação dos modos de comparação de diferentes capacidades de trabalho, visando a torná-las relativamente independentes dos atributos individuais dos trabalhadores; melhor dizendo, visando a torná-las independentes da arbitragem do capital no julgamento desses atributos (CADRES, 1984). 
Essas normas darão origem às classificações profissionais, que ordenam hierarquicamente as qualificações de um grupo de indivíduos por meio dos postos de trabalho e definem, assim, as regras que irão reger a trajetória profissional dos assalariados, isto é, o contrato de trabalho: o recrutamento, a remuneração básica, os níveis e a hierarquia de salários, a promoção (Eyraud, s.d.; Jobert, s.d.; Neffa, s.d.; Tanguy, 1997b). Há, portanto, nesse momento, o início de uma estruturação coletiva de normas para direitos e regulaçôes do uso do trabalho, fundada em negociações, convenções e acordos, que tinham por base justamente a questão da qualificação:

O caráter central de que a noção de "qualificação" se reveste na França lhe é conferido pelo fato de ela fundamentar um conjunto de práticas que visam a relacionar o funcionamento do sistema educativo e do sistema produtivo. Assim compreendida, essa noção vai conduzir, logo após a Segunda Guerra Mundial, a diversas medidas institucionais, entre as quais as grades de classificação que repousam num compromisso social ao termo do qual são definidos os princípios de relação de duas distribuições hierarquizadas, a dos indivíduos segundo suas capacidades e a dos empregos aos quais são atribuídas remunerações. Um tal trabalho de formalização e de codificação realiza-se geralmente na escala dos ramos profissionais, lugar de organização privilegiado pelos empregadores e pelos assalariados na medida em que eles têm acesso, assim, à ação política e social. $^{* * *}$ (Tanguy, 1997b, p. 400)

É nesse momento, portanto, que a qualificação do trabalho aparece como central: ela se torna não apenas um aspecto da prática política e social como, também - e talvez por isso mesmo -, um conceito a ser problematizado. Melhor dizendo, a qualificação vai se transformando em um conceito à medida que permite análises do conteúdo do trabalho, da evolução da organização da produção, das avaliações e classificações sociais expressas nas convenções coletivas, do funcionamento do mercado de trabalho (Saglio, 1998).

É preciso ressaltar também que essa formalização da qualificação em classificações profissionais significou, na França do pós-guerra, a padronização dos conteúdos da qualificação: a cada profissão, a cada posto de trabalho correspondia um nível escolar; uma vez adquiridos os co-

*** Todas as traduções deste texto são livres e de minha inteira responsabilidade.

Educ. Soc., Campinas, vol. 25, n. 87, p. 353-382, maio/ago 2004 
Algumas reflexões sobre a qualificação do trabalho a partir...

nhecimentos dessa categoria profissional, o trabalhador poderia ali permanecer sem que lhe exigissem novas aprendizagens. Em outras palavras, havia um ordenamento social das profissões e da estrutura de cargos e salários relativamente sólido e estável (Paiva, 1995), legitimado e hierarquizado pelo diploma, pelo tempo de formação - tempo de formação necessário para a execução de uma determinada tarefa (Dadoy, 1987) -, o que significa dizer que somente os conhecimentos formais e explícitos eram valorizados, validados e codificados. ${ }^{3}$

Havia, assim, uma estável correspondência entre "nível de formação" e "nível de qualificação" que garantia aos trabalhadores uma carreira profissional sólida e previsível e permitia um planejamento educacional a partir da análise das ocupações. Essa correspondência instituída por esse sistema de classificação francês foi, aliás, um dos pilares sobre os quais se sustentou o crescimento verificado no pós-guerra, quando se alcançou "um equilíbrio estável que marcava correspondências claras entre o sistema educativo, o sistema produtivo e o sistema social" (Lichtenberger, s.d., p. 31).

Para os propósitos deste texto, é muito importante enfatizar que essas estabilidade e solidez presentes na estrutura profissional do chamado "modo de regulação fordista" implicavam uma certa maneira de compreender a qualificação: uma vez que as qualificações se referiam a uma hierarquização das profissões de cada ramo específico, hierarquização esta estabelecida pelo tempo de formação; uma vez que, adquiridos o saber e o "saber-fazer" de uma dada categoria profissional, o trabalhador poderia ali permanecer de uma vez para sempre; uma vez que, portanto, apenas os conhecimentos explícitos eram codificados; a qualificação foi e ainda é assimilada, por muitos, a um estoque de saberes especializados, formais e estáticos.

Assim, na medida em que esse "modo de regulação" entra em crise, não só a estabilidade e a solidez da referida hierarquia de qualificações tornam-se fluidas, como se tem o questionamento do próprio conceito de "qualificação".

Crise do chamado "modo de regulação fordista" e a disputa em torno de um conceito: "qualificação(ôes)" versus "competência(s)"

Com as transformações tecnológicas, econômicas, políticas e culturais que atingiram o mundo do trabalho a partir dos anos de 1970, o "modo de regulação fordista" e as técnicas tayloristas de produção 
parecem esgotados para superar a crise, e inicia-se então a "passagem" desse modelo para o chamado "regime de acumulação flexível", como a forma "encontrada" pelo capital para superar a crise iniciada na década de 1970 (Harvey, 1996). Ainda que a passagem de um "paradigma" a outro deva ser pensada como um processo complexo e contraditório que evidencia uma crise, e não uma supressão acabada de um "modelo" por outro, o fato é que as novas bases tecnológicas introduzidas pela chamada “Terceira Revolução Industrial” (microeletrônica e robótica, microbiologia e novas fontes de energia) forneceram as condições para uma reestruturação produtiva apoiada na referida produção enxuta, integrada e flexivel. ${ }^{4}$ Por serem programáveis e, portanto, flexíveis, as máquinas baseadas em tecnologia microeletrônica atenderam as necessidades do mercado instável e permitiram a retomada dos ganhos de produtividade, ao assegurar uma nova economia do tempo e do controle, que permite, por sua vez, otimizar recursos e reduzir drasticamente os tempos de produção (Coriat, 1983, 1994; Leite, 1994).

Se todo esse processo também traz consigo uma forte segmentação do trabalho, o que faz com que a integração e a flexibilização não atinjam todos os trabalhadores da mesma maneira, deve-se notar que algumas de suas conseqüências afetaram a organização, as relações e os conteúdos do trabalho dentro das empresas. Diante da automação flexível como forma de contornar a crise, elas introduziram, ao lado de transformações tecnológicas de base física, mudanças organizacionais: as decisóes operacionais deveriam ser descentralizadas em virtude da velocidade das mudanças e os trabalhadores de todos os escalóes seriam chamados, a todo momento, a participar desse processo de inovação rápida, tomando decisōes e enfrentando os problemas aleatórios e imprevistos presentes neste "novo" modo de produzir. Assim, tem-se demandado dos trabalhadores não apenas conhecimentos formais e explícitos objetivados pelo diploma, mas também amplas habilidades cognitivas e comportamentais, tais como iniciativa, responsabilidade, autonomia, criatividade, cooperação, liderança, flexibilidade etc., para lidar com tarefas cada vez mais abstratas e complexas. Em uma palavra, as referidas mudanças estariam colocando em xeque o posto de trabalho e o trabalhador especializado e exigindo um trabalhador polivalente. ${ }^{5}$

A ênfase na "polivalência", entendida como um conjunto de capacidades que possam enfrentar a complexidade e a imprevisibilidade do "novo" modo de produzir, significa a passagem do conceito de "qualificação" para 
Algumas reflexões sobre a qualificação do trabalho a partir...

o de "competência". A competência pode ser definida como a tradução dessas capacidades numa tomada de iniciativa e num assumir de responsabilidades por parte do trabalhador perante os eventos produtivos - situações surpreendentes que ocorrem na produção (Zarifian, 1997 e 1998). A competência é, pois, um atributo que remete à subjetividade do indivíduo, e relaciona-se com a sua capacidade de mobilizar os saberes e as atitudes necessárias para, de forma autônoma, resolver problemas em uma situação específica (Machado, 1998; Tanguy, 1997a e 1997c).

Algumas das principais características do "modelo de competência” dizem respeito à sua forma de organização e de gestão do trabalho: no primeiro caso, o controle dar-se-ia por objetivos e resultados, e não mais por tarefas, já que a prescrição estaria sendo substituída por um trabalho flexível que, por isso mesmo, demanda os aspectos subjetivos da qualificação. No segundo, o recrutamento, a remuneração e a promoção dentro das empresas integradas e flexíveis seriam realizados não mais por cargos mas por competências, o que significa um deslocamento da rede de qualificações do posto de trabalho para o indivíduo. Na França, essa mudança expressa pelo conceito de "competência" se opõe à idéia de qualificação porque a definição das qualificaçōes deixa de ser feita por categorias e negociada coletivamente e se transforma em competências avaliadas individualmente e por cada empregador (Dubar, 1998a).

Dessa forma, à medida que o posto de trabalho vê seu desaparecimento, as formas tradicionais de classificação das qualificações e hierarquização dos salários que dele derivaram - produzidas coletivamente - são questionadas. Colocando em xeque a estrutura profissional baseada nos postos de trabalho, a realidade empírica e/ou a teoria científica têm produzido uma nova maneira de designar o trabalho sua seleção, remuneração, promoção etc. -, centralizada nas competências, justamente porque se pressupõe ser ela a fornecedora da flexibilidade exigida atualmente e a promotora do reconhecimento e da valorização dos aspectos subjetivos, não-formais e implícitos da qualificação. No singular, a competência expressa uma mudança na organização e nas relaçôes sociais; no plural, ela designa as transformaçôes nos conteúdos profissionais (Zarifian, 1997 e 1998).

Vê-se, assim, que as modificações nos conteúdos da qualificação provocam uma mudança no seu próprio conceito. Isso porque a qualificação foi, e ainda é - independentemente das concepções de Friedmann e Naville -, associada, pela prática social e pela literatura, ao "modo de 
regulação fordista" e às técnicas tayloristas de produção, nas quais prevalecia o sistema de codificação do trabalho baseado na classificação de qualificaçôes, identificadas, por sua vez, como um estoque de conhecimentos formais, específicos e rígidos, conferidos de uma vez para sempre pelo diploma. Esse modelo de gestão do trabalho que vigorou - na prática e conceitualmente - durante o fordismo, especialmente na França, parece, assim, não ser mais condizente com o "novo paradigma produtivo".

Defende-se aqui a hipótese de que, se a substituição da qualificação pela competência é possível, ela requer, primeiramente, uma melhor compreensão teórica do conceito de "qualificação", para além de sua associação empirica ao "modo de regulação fordista" e às técnicas tayloristas de organização do trabalho. Passemos a ela.

A concepção de qualificação do trabalho em Georges Friedmann e Pierre Naville

Georges Friedmann é considerado o "pai fundador" da sociologia do trabalho francesa. Vivendo no contexto da mecanização e da organização do trabalho taylorista mas quando, ao mesmo tempo, prenunciava-se a automação, ele faz suas pesquisas com base na observação direta nas empresas, a fim de visualizar, nas condições concretas de diversas situaçóes de trabalho, os efeitos do progresso técnico sobre o trabalho humano.

Ainda que a qualificação propriamente dita não seja definida sistematicamente como categoria teórica em sua obra (Dadoy, 1987), suas análises trazem-na implicitamente, à medida que ele vai refletindo sobre quais seriam os elementos, os conteúdos da qualificação. Resumidamente, pode-se dizer que, em Friedmann (1946, 1950, 1956, 1977), a qualificação está relacionada principalmente à complexidade da tarefa e à posse de saberes exigidos para desenvolvê-la; ou seja, à qualidade do trabalho e ao tempo de formação necessário para realizálo. Apesar de tender, em vários momentos, para uma concepção mais ampla da qualificação, o autor concentra sua reflexão na apropriação do saber do trabalhador pela máquina e/ou pela organização capitalista e toma a qualificação nela mesma, como uma "coisa" que pode ser mensurada pelo grau e pela freqüência de atividade intelectual que o trabalho exige para ser executado (Alaluf, 1986). É assim que ele concentra esforços para concluir por uma desqualificação ou requalificação 
Algumas reflexões sobre a qualificação do trabalho a partir...

do trabalho como decorrência das transformações técnicas e organizacionais; com idas e vindas, ele nota, em contrapartida,

tendências inversas, que alimentam os primeiros discursos sobre a automação e o aparecimento de novas qualificaçôes que começavam a surgir nesse período, o que o conduziu, assim, a formular, pela primeira vez, a tese da polarização das qualificações, que conhecerá o sucesso que nós sabemos, 30 anos mais tarde. (Dadoy, 1987, p. 18)

Debates teóricos iniciados na França nos anos de 1980, reconstituindo os vários pontos de vista sobre o sentido que se tem dado à qualificação, denominam "essencialista" ou "substancialista" essa abordagem que parte da qualidade e da complexidade das tarefas para chegar aos atributos dos trabalhadores necessários para desempenhá-las (Campinos-Dubernet \& Marry, 1986).

Seu objetivo é comparar, mensurar sobre uma escala única (a partir de um indicador desta complexidade do trabalho - o mais freqüentemente de formação), as diferentes qualidades da força de trabalho, a um momento dado, mas também no decorrer da história: ela faz, para isso, a hipótese de uma correspondência estreita entre o grau de complexidade de um conjunto de tarefas e as aptidões ou competências manifestadas pelos trabalhadores na execução dessas tarefas. A qualificação coincide assim com a estrutura da divisão do trabalho, a qual depende de maneira essencial da tecnologia utilizada ou das "relações capitalistas". (Campinos-Dubernet \& Marry, 1986, p. 199)

Friedmann, tido como o precursor dessa linha de pensamento, acaba, assim, por considerar a qualificação do trabalho - conteúdo do trabalho -, por um lado, e a qualificação do trabalhador - saber e "saber-fazer" -, por outro, necessárias para a execução desse trabalho.

A essa visão se opõe a chamada visão "relativista" - representada inicialmente por Pierre Naville -, que não concebe a qualificação apenas do prisma da técnica e do conteúdo do trabalho (ainda que os considere), mas antes como sendo um processo e um produto social, que decorre, por um lado, da relação e das negociaçóes tensas entre capital e trabalho e, por outro, de fatores socioculturais que influenciam o julgamento e a classificação que a sociedade faz sobre os indivíduos. Senão, vejamos.

Naville inicia suas pesquisas sobre o trabalho em meados dos anos de 1950, portanto uma década depois de Friedmann. Se, por 
um lado, as obras deste último ainda eram a primeira referência na sociologia do trabalho, por outro, as interrogaçóes sobre as conseqüências técnicas, econômicas e sociais da automação haviam se intensificado: as opiniōes as mais contraditórias estavam polarizadas "entre os friedmannianos que pensa[va]m o trabalho em migalhas [era] a forma dominante do momento e risca[va] permanecê-lo por muito tempo, e os otimistas que apoia[va]m a difusão rápida da automação" (Dadoy, 1984, p. 70).

As reflexões de Naville sobre a qualificação estão estreitamente relacionadas às da automação, apesar da distância de publicação das duas obras referentes aos temas: em 1956, ele lança o Essai sur la qualification du travail, e é somente depois de quase uma década realizando pesquisas empíricas sobre a automação que ele publica a síntese de sua reflexão no livro Vers l'automatisme social?

Para Naville, responder às questões "o que é a qualificação?” e "o que é um trabalhador qualificado?" exige primeiramente reconhecer a diversidade contida nesta noção, expressa nas diferentes condições sociais, econômicas, políticas e culturais nas quais ela se inscreve. $\mathrm{O}$ autor possui, assim, uma forte perspectiva histórico-comparativa - que o afasta do estruturalismo então em voga (Tanguy, 1996) -, já que considera a qualificação uma noção situada no espaço e no tempo. Ora, isso significa que qualquer sociedade terá seus critérios para definir e julgar o que é um trabalho qualificado.

A sociedade moderna impõe, assim, uma certa forma ao significado da qualificação e à sua aquisição. O que é específico à análise da qualificação no modo de produção capitalista, ou melhor, nos regimes salariais? Ao introduzir a separação do trabalhador do produto de seu trabalho, o salariado também separa a formação do exercício do trabalho: antes, não se preparava o homem para o trabalho; ele aprendia no próprio trabalho. Instaura-se assim, simultaneamente, um processo de diferenciação entre qualificação do trabalhador e qualificação do posto de trabalho. Se "até sua época [de Adam Smith], a qualidade do trabalho é considerada um tipo de perfeição independente do sistema econômico, estreitamente ligada à pessoa" (Naville, 1956, p. 20), no capitalismo, diferentemente da heterogeneidade dos métiers tradicionais, predomina "uma capacidade de trabalho simples e ordinariamente indiferenciada, ao mesmo tempo parcelar e universalmente transferível" (idem, ibid., p. 26), ou seja, uma equivalência 
Algumas reflexões sobre a qualificação do trabalho a partir...

qualitativa de todas as atividades. Em outras palavras, quando a qualificação não era senão uma capacidade de trabalho, o problema da hierarquia de qualificações não se colocava na prática cotidiana (CADRES, 1984).

Ora, isso significa que, se a qualificação não nasce com o salariado, é com ele que ela se torna mensurável: as qualidades das pessoas passam a ser avaliadas economicamente, ${ }^{6}$ por meio de processos sociais de hierarquização que transformam essas qualidades em quantidades. Os atributos da força de trabalho, adquiridos no seio do sistema educativo, são comprados por um salário para permitir a criação e a circulação de bens e serviços necessários para a produção e reprodução da sociedade. A qualificação, caracterização da qualidade mais ou menos elevada do trabalho, situa-se assim na convergência do sistema produtivo e do sistema educativo (Campinos-Dubernet \& Marry, 1986): "As aptidóes formadas pela escola e pela educação cristalizam-se em uma aptidão específica que, quando reconhecida socialmente, torna-se qualificação" (Cardi, 1997, p. 104). Dito de outra forma,

os níveis de qualificação do trabalho exprimirão, afinal de contas, os valores econômicos que lhe são inclusos e, em resultado, o julgamento mais ou menos favorável trazido sobre eles. Ao passo que a capacidade de trabalho é o objeto de um mercado - mercado privado ou mercado de Estado -, é inevitável que ela seja avaliada diferentemente conforme o custo de sua formação e a necessidade que a economia tem dela: daí resulta sua apreciação qualitativa como qualificação. (Naville, 1956, p. 135-136; grifos nossos)

Para o autor, o salariado significa, em uma palavra, a separação do trabalhador de seu trabalho; o trabalho distancia-se daqueles que o produzem, para subordiná-los e arrastá-los em seu movimento. Em contrapartida, a extensão do salariado, associada às conseqüências da automação, manifesta-se na dissociação crescente entre o trabalho das máquinas e o trabalho dos homens. A desconexão progressiva entre os sistemas técnicos e as atividades humanas acarreta também uma disjunção entre os ciclos do tempo da máquina e os ciclos do tempo do homem. As técnicas vão ganhando cada vez mais autonomia e rompem com a relação direta do trabalhador com os materiais, as ferramentas e os produtos. O movimento contínuo de separação do trabalhador de seu trabalho instaurado pelo salariado (que Naville apre- 
ende por um quadro teórico) é assim reforçado pelas transformações técnicas (que ele observa empiricamente).

Naville situa-se, assim, em um registro bem mais amplo: uma vez que o regime do salariado separa o trabalhador de seu trabalho ou, como diz Alaluf (1986, p. 55), separa "a atividade profissional do trabalhador entre um período de educação não remunerada e uma atividade prática remunerada", a qualificação não pode ser derivada do conteúdo do trabalho mas, antes, deve ser vista por meio da relação entre essas duas esferas. Em outras palavras, com o salariado, a qualificação passa "da esfera do trabalho para aquela das relaçóes entre formação e emprego assalariado” (Dubar \& Tripier, 1998, p. 143). Diferentemente de Friedmann, portanto, não basta apenas pensar na qualificação do trabalhador e na do trabalho, mas é preciso relacionálas e ver os conflitos existentes entre as qualificaçóes adquiridas pelos indivíduos e as qualificaçóes requeridas pela "indústria” - ou seja, pela sociedade, para satisfazer suas necessidades.

Se a qualificação deve ser vista sob o ângulo de sua apreciação social, isto é, da produção de hierarquias profissionais, ela não pode ser definida como uma "coisa", um atributo do qual se pode caracterizar a essência, nem pode ser fundamentada pelas características do trabalho a realizar.

Nós seríamos levados (...) a dizer que o fenômeno da qualificação do trabalho não existe por si, que ele não é, em suma, senão a forma muito relativa de certos aspectos da estrutura da indústria vistos em seus efeitos sobre o emprego; que sua determinação quantitativa não tem nada de natural, e que o caráter "objetivo" dessa determinação é um artifício pelo qual as instituições codificam certos tipos de hierarquia técnica inerentes às nossas sociedades antagônicas. (...). A qualificação não pode jamais ser apreendida nela mesma. Ela se apresenta sempre como uma relação, e uma relação de elementos múltiplos. (...). Fundamentalmente, é uma relação entre algumas operaçôes técnicas e a estimativa de seu valor social, e esta parece ser a visão sociológica mais abrangente que dela se pode ter. (Naville, 1956, p. 129)

Sociologicamente, então, a qualificação do trabalho é uma relação social complexa porque ela põe em jogo "algumas operações técnicas e a estimativa de seu valor social” (idem, ibid.), valor este estimado economicamente mas que também é recoberto pelas avaliações sociais de alcance mais vasto. Daí decorre que a qualificação varia 
Algumas reflexões sobre a qualificação do trabalho a partir...

conforme a época, de país para país, e até mesmo de setor para setor, em função de aspectos técnicos e de organização do trabalho, sim, mas também, e principalmente, em função de fatores morais e políticos presentes no julgamento que a sociedade faz sobre a qualidade dos trabalhos necessários a sua reprodução. Se as conseqüências da automação, associadas à extensão do salariado, também promovem a dissociação crescente entre o trabalho das máquinas e o trabalho dos homens, isso apenas ratifica a tese de que a qualificação do trabalho deve ser vista não "como um tipo de substância, de 'coisa' estreitamente dependente das circunstâncias técnicas imediatas [e individuais] em que ela se revela", mas como "a apreciação social do valor diferencial dos trabalhos" (Naville, apud Alaluf, 1986, p. 129-130). No contexto da automação, torna-se ainda mais claro que a visão que deriva a qualificação diretamente da qualidade do trabalho, ou seja, que enfatiza a "despossessão" dos saberes do trabalhador pelo progresso técnico e/ou pelo capitalismo, perde toda sua consistência. Assim concebida, essa teoria da qualificação faz o salariado lamentar as condições anteriores de sua própria exploração (Alaluf, 1986).

Assim, se, no contexto da automação, o homem transfere sua qualificação à máquina e, neste sentido, vai se liberando da produção, essa transferência não é encarada por ele como sinônimo de desqualificação. Dizer que os homens e as máquinas operam em registros diferentes é o mesmo que dizer que as aparentes transferências de funções entre homens e máquinas não são simplesmente transferências de saberes e capacidades (Stroobants, 1993b). Na medida em que a qualificação coloca em relação operações técnicas e os critérios para avaliálas, isto é, "estabelece uma relação entre duas relações cujos termos são flutuantes, como se poderia medir sua evolução positiva ou negativa?" (idem, ibid., p. 97). Se Naville fala em "movimentos constantes de desqualificação-requalificação" (Naville, 1956, p. 38, 146), não é num sentido valorativo, isto é, de perda ou da recuperação de saberes, mas antes no sentido de reconhecimento e existência social.

Da mesma forma, se a automação permite uma reunião das operações automatizadas na máquina, isso não significa, de forma nenhuma, uma possível "recomposição" das capacidades profissionais anteriores ao parcelamento das tarefas e dos conhecimentos em um mesmo trabalhador, mas antes um deslocamento de saberes (Dadoy, 1984), o que implica não uma "requalificação", mas sim um maior distanciamento 
do trabalhador de seu trabalho. Os trabalhos do autor invalidam, assim, a tese então em voga - e retomada nos anos de 1980 - de uma ligação mecânica entre automação e aumento das exigências de "qualificação", ou seja, de uma possível "recomposição" do trabalho e dos saberes sobre um mesmo trabalhador, o que provocaria a sua requalificação. Uma vez que não se trata da recuperação possível de um domínio perdido nem da comparação de qualidades de trabalho de diferentes lugares e momentos, em termos de aumento ou diminuição, não se deve falar em "requalificação" do trabalho, mas sim em qualificação nova e antiga, em transformação das qualificações.

Em resumo, o que Naville não concebe - e o que em última análise o difere da visão "substancialista" - é que se tome a qualidade do trabalho para determinar diretamente a qualificação, o que acaba por lhe conferir um caráter "essencial" ou "substancial" (CampinosDubernet \& Marry, 1986): “A qualificação, sendo feita de qualidades, estas são transferidas à máquina, o capitalismo organizando assim a desqualificação do maior número" (Alaluf, 1986, p. 318). São os termos da questão que deveriam, pois, ser modificados: não se trata de saber se o capitalismo ou a técnica aumentam ou não a qualificação, mas de entender que, no salariado, a qualificação remete a uma relação social, "que resulta da distinção mesma entre a qualificação dos empregos e a qualificação dos trabalhadores" (Hirata, 1996, p. 132).

Partindo da constatação de que a qualificação se situa na relação entre o sistema educativo - no qual se produz o valor de uso das qualificações - e o sistema produtivo - no qual essas qualificações são reconhecidas socialmente, em termos de salários e de prestígio, ou seja, no qual elas se tornam valor de troca -, a perspectiva de Naville revela a necessidade de "sair da empresa", para avaliar as formas jurídicas ou institucionais que a qualificação pode tomar, como classificações, índices de salários, categorias estatísticas etc. É por considerar a qualificação uma relação social derivada de conflitos diversos, rompendo assim com a perspectiva que deduz da qualidade do trabalho sua medida em termos de qualificação (Alaluf, 1986), que Naville é considerado o precursor da chamada visão "relativista": ${ }^{7}$

Para esta (...) corrente, a qualificação é um enjeu, ${ }^{8}$ ela é eminentemente relativa. Seu conteúdo varia no tempo, se bem que se torna difícil, quase sem significação, comparar qualidades de trabalho que jamais se reencontram no 
Algumas reflexões sobre a qualificação do trabalho a partir...

mercado de trabalho. A definição da qualificação e sua medida são muito conflituosas, pois atrás dela joga o problema do salário, do conflito coletivo e individual, ligado ao problema da partilha do valor criado. Esta concepção da qualificação foi iniciada por Pierre Naville em seu Essai sur la qualification du travail de 1956 e retomada, a partir do fim dos anos de 1960, por um conjunto de trabalhos de sociologia do trabalho (...) [que], quaisquer que sejam suas diferenças (nos encaminhamentos, nos objetos tratados, nos métodos de investigação empírica), têm em comum o fato de abordar a qualificação menos por ela mesma que por meio dos enjeux, lutas e processos sociais que concorrem para sua codificação (nas classificaçōes, por exemplo) e para sua avaliação (em termos de salário, mas também de prestígio). (Campinos-Dubernet \& Marry, 1986, p. 206)

Apesar dessa ampliação representada pela perspectiva navilleana, na medida em que, em sua época, o emprego era disponível e o desemprego, fraco, a prioridade era colocada mais sobre a definição das qualificações e das condições de trabalho que sobre as relaçóes de emprego presentes no mercado de trabalho (Erbès-Seguin, 1999). Alaluf (1986) também mostra que a tese da "despossessão" do saber dos trabalhadores, de sua desqualificação, exerceu e ainda exerce um grande fascínio sobre a sociologia francesa, primeiro porque os sociólogos se concentraram durante muito tempo sobre as indústrias metalúrgicas, nas quais a "parcelização" das tarefas adquiriu a forma mais evidente, e também por causa da metodologia adotada, apoiada sobre o discurso dos próprios trabalhadores, que falam em termos nostálgicos do trabalho passado e ocultam suas dificuldades, porque sentem a perda da identidade profissional e da coalizão operária. Por causa disso, por tentar apreender a qualificação nela mesma, no locus do trabalho, por meio do grau e da freqüência de inteligência que ela requer, os sociólogos tenderam a vêla em termos evolutivos e associaram sua evolução à tecnologia, aproximando-se muito da perspectiva iniciada por Friedmann. Porém, identificando a qualificação à tecnologia, fazem-na desaparecer como conceito autônomo (Campinos-Dubernet \& Marry, 1986).

Simultaneamente, alguns estudos atuais sobre as mudanças no mundo no trabalho, ou melhor, sobre o trabalho formal no interior das empresas, ao enfatizar o "enriquecimento" do trabalho e a participação e valorização dos trabalhadores, por meio dos diversos atributos expressos no "modelo de competência", trazem o risco de que haja um retorno para essa visão "substancialista", ou seja, para a dimensão da qualidade 
do trabalho e das características individuais para realizá-lo - até por causa da forte ligação da noção de competência com as ciências que se ocupam do ensino-aprendizagem, da cognição e da linguagem humana. Dito de outro modo, as constatações de "requalificação" ou de "reprofissionalização", longe de refletirem uma mudança de paradigma na sociologia do trabalho, expressam o mesmo raciocínio que as teses de "desqualificação" ou de "polarização das qualificações", porém com sinais invertidos: em todos os casos, supóe-se que o conteúdo, a complexidade, a qualidade, enfim, a substância do trabalho (negativa, depois positiva) contém os determinantes da qualificação (Alaluf, 1986 e 1995; Stroobants, 1993a e 1993b). Ora, se esse risco existe na França, a mesma tendência também parece manifestar-se no Brasil, já que o discurso sobre a(s) competência(s) tem tido aqui uma influência significativa.

É neste ponto que acreditamos que o conceito de "qualificação" elaborado por Naville deve ser recuperado e mantido, primeiro porque ele é mais amplo que o de "competência" e, segundo, porque é por meio dele que se pode compreender a pertinência da sua disputa com a noção de "competência" no contexto brasileiro.

\section{Qualificação: mais ampla que a competência}

Se Naville deixa de lado vários aspectos que, em sua época, não eram problemas (desemprego, precarização e desregulamentação do trabalho etc.), sua definição da qualificação como uma relação social permanece extremamente atual, porque, no regime do salariado (que separa o trabalhador de seu trabalho), as qualificaçōes profissionais que, em princípio, remetem a capacidades qualitativas - são apreciadas por meio de sua hierarquização nas classificaçōes profissionais que medem quantitativamente essas capacidades por meio do salário. Assim, no salariado, a qualificação do trabalhador tem que ser relacionada à qualificação do trabalho, relação que se expressa na "oposição entre a cristalização das qualificaçôes adquiridas e a fluidez das qualificaçôes requeridas", o que gera uma contradição social, na medida em que o trabalhador "considera sua qualidade profissional como uma aquisição definitiva ligada à sua pessoa (...) e a 'indústria', ao contrário, exige um envolvimento permanente resultante de necessidades móveis" (Naville, 1956, p. 147-148), para a sua manutenção e re- 
Algumas reflexões sobre a qualificação do trabalho a partir...

produção. É assim que se tem "a relatividade das qualificaçôes adquiridas, que podem, de um dia para o outro, não ter mais significação prática, perdendo assim toda sua existência" (idem, ibid., p. 38).

O fato de haver uma diluição dos postos de trabalho e das profissões e de haver novas práticas de trabalho para além do assalariado formal que demandam atributos mais subjetivos não invalida esta argumentação, isto é, não significa que as qualificações sejam remetidas, de fato, à qualidade dos indivíduos, pois as atividades dos homens continuam sendo avaliadas por meio de seu valor econômico, ou seja, continuam sob o domínio da relação salarial. Em contrapartida, essas mudanças podem implicar, sim, um novo tipo de classificação. Se, como mostrou Naville, as classificações contêm um elemento artificial e, portanto, não correspondem ao trabalho de fato realizado na prática, isso significa que elas não são imutáveis, mas sim objeto de "contestações" permanentes dos critérios "cristalizados" nas hierarquias de qualificação, tanto pelos empregados como pelos empregadores, ainda que por razões opostas (ibid., p. 8, 67, 130). Em outras palavras, sempre haverá ajustamentos freqüentes para a redefinição das qualificações em novas convenções, que são construídas e adaptadas às relações de força contraditórias presentes em um dado lugar e momento histórico, e que acabam, portanto, integrando interesses particulares e divergentes em um vocabulário comum que possibilita o conflito, o intercâmbio e a cooperação (Lichtenberger, s.d.). Neste sentido, a gestão do trabalho pela competência poderia ser vista como uma nova forma de classificação dos trabalhadores, mais próxima do trabalho real?

Uma vez que a transformação tem um papel fundamental no pensamento navilleano, não se poderia dizer que a substituição do modelo de gestão do trabalho baseado na qualificação para um assentado sobre a competência é, em si, maléfica: em primeiro lugar, porque a padronização das qualificações em classificações profissionais objetivas e impessoais é uma especificidade da sociedade francesa (Saglio, 1998), o que significa que, em outros lugares, pode haver outros tipos de hierarquização que não são necessariamente ruins para os trabalhadores; em segundo, porque, se há uma diluição do posto de trabalho e da especialização que lhe é associada, as classificações não podem ficar à parte dessa realidade concreta do trabalho, que demanda "polivalência" e que incita a uma hierarquia mais conectada com os indivíduos do que com os postos de trabalho (Lichtenberger, s.d.); finalmente e decorrente daí, 
porque esse novo modelo é fruto das próprias relações sociais entre empregados e empregadores, ou seja, as classificações só adquirem sentido se construídas pelas próprias pessoas (Dadoy, 1990). Porém, num contexto em que há uma assimetria nas relações de força, ou seja, em que um dos lados dessa relação se vê em posição bastante desfavorecida para barganhar condições de trabalho e salário, podemos dizer que Naville enfatizaria, ao menos, a importância de se pensar os conceitos criticamente: da mesma forma como ele procedeu com as "aptidôes", o uso da noção de "competência" e das técnicas que a acompanham também deveria ser precedido de uma análise prévia de seus fundamentos e das práticas sociais que ela autoriza (Tanguy, 1996).

É assim que, se a competência era, até meados da década de 1990, uma noção bastante fluida e vaga no âmbito do pensamento acadêmico (Hirata, 1996), essa imprecisão tem sido revertida por alguns autores que procuram defini-la melhor, dentre os quais se destaca Zarifian (1994, 1995, 1997, 1998). Este autor tenta dar um estatuto científico à noção, por meio de uma perspectiva multidimensional: de um lado, ela se refere à capacidade para agir em situações específicas e imprevisíveis, capacidade esta que deriva da inteligência prática apoiada nos conhecimentos adquiridos que são transformados; de outro, ela designa o fato de ser reconhecida pelo julgamento dos outros, tanto em termos sociais quanto financeiros. Em uma palavra, a competência é simultaneamente uma tomada de responsabilidade (pelas próprias pessoas, e não delegada) e o reconhecimento social dessa tomada de responsabilidade. Nesses dois casos, o que importa não é apenas a bagagem de conhecimentos, mas a autonomia manifestada no domínio de situações e o reconhecimento por meio do qual essa autonomia pode aflorar. Essa definição supõe, portanto, que as empresas se transformem em "organizações qualificantes", isto é, que confiem no engajamento de responsabilidade de seus empregados e se comprometam com a evolução de seu percurso profissional. Para Zarifian, privilegiar a subjetividade não significa, todavia, renegar o lado social: a competência não deveria, assim, remeter a um indivíduo isolado, mas antes a uma rede de comunicação e de co-responsabilidades, que remeteria a um coletivo de trabalho. Por tudo isso, o autor prefere então usar o termo "competência", pois a definição de qualificação fica presa ao falso dilema entre a qualificação do emprego - que não dá conta do trabalho real - e a qualificação do individuo - que não abrange a dimensão do reconhecimento. 
Algumas reflexões sobre a qualificação do trabalho a partir...

Apesar desta definição ampliada, o que se quer mostrar aqui é que, do ponto de vista teórico, a qualificação, tal como concebida por Naville, não só está longe de ser um conceito estático, que designa as qualidades dos trabalhadores objetivadas pelo diploma, como também é mais ampla que a competência e a engloba, pois é a qualificação que dá conta dos aspectos sociais, econômicos, políticos e culturais presentes na classificação e na hierarquização dos empregos e das profissões.

Se o salariado separa o trabalhador e sua formação de seu trabalho, isso significa que, se a qualificação é em grande parte determinada no quadro do sistema escolar, ela escapa largamente à escola, pois não pode manifestar-se e ser sancionada senão com relação ao trabalho (Alaluf, 1986): "A equação [entre ensino, formação e qualificação] oculta o fato de que a qualificação não é uma propriedade conferida pelo sistema educativo aos indivíduos, mas uma relação social que combina vários parâmetros e que é determinada pelo mercado" (Tanguy, 1997b, p. 395). Um aumento nas exigências de formação não significa necessariamente, portanto, um aumento da qualificação. Da mesma forma, não se pode fazer da aprendizagem um sinônimo do emprego ocupado: há uma diferença entre aprender a mecânica e ser mecânico em uma dada empresa (Alaluf, 1986). Basta lembrar, para isso, que as "aptidōes" formadas pela escola só se tornam qualificação quando são reconhecidas socialmente, isto é, quando se tornam úteis à sociedade. Como diz Naville, "um métier que perde toda justificação econômica pára de representar um valor social, que anteriormente foi estimado e considerado" (Naville, 1956, p. 130-131).

Stroobants (1993a e 1993b) mostra que a problemática da qualificação deve interessar àqueles que falam mais de competência que de qualificação, justamente por causa da ênfase de Naville para não se confundir as características dos trabalhadores com aquelas do trabalho. Se a qualificação não é uma "coisa", uma "substância", diz Naville, "é porque não existe nenhum meio direto e 'objetivo' de qualificar um conjunto de postos por razões puramente técnicas". Deriva daí que "as operações, tarefas ou a qualidade do trabalho não determinam a maneira pela qual as competências dos trabalhadores serão valorizadas em termos de qualificação" (Stroobants, 1993a, p. 278). Um trabalho mais complexo, que demande competências variadas e elevadas, não será necessariamente mais qualificado, pois pode não ter, socialmente, reco- 
nhecimento simbólico e/ou financeiro. Dito de outro modo, as competências referem-se aos atributos dos trabalhadores, mas não dão conta de sua valorização efetiva.

A qualificação não pode, assim, ser reduzida às propriedades intrínsecas dos indivíduos - suas "aptidōes", "habilidades" e "competências" -, pois ela depende de sua realização no mercado de trabalho, local onde se concretizam as representações sociais que acabam exclusivizando certos postos a determinados segmentos. A qualificação também não pode referir-se apenas aos atributos dos indivíduos, pois estes podem possuir - e normalmente possuem - capacidades de que não necessitam nem podem utilizar em seu trabalho. A competência é, portanto, apenas um dos elementos da qualificação, e permanece submissa a ela, não só porque ela diz respeito aos aspectos individuais das capacidades de trabalho e, portanto, remete menos imediatamente às operaçóes sociais de classificação e hierarquização dos indivíduos e dos empregos (Tanguy, 1997c) como também porque somente quando ela é reconhecida e instituída socialmente - em termos sociais e monetários - é que ela se torna qualificação.

Além disso, essa mesma autora indaga se existe, de fato, um novo "modelo de competência" ou se se trata antes de uma nova maneira de representá-la. Isso porque

este mesmo modelo, aplicado ao passado, pode nos revelar várias competências insuspeitadas nos trabalhadores, (...) [já] que estratégias cognitivas complexas subentendem as atividades as mais rotineiras. As novas competências assinaladas não são assim sem precedentes. Sua descoberta parece mais resultar de uma maneira de ver que de uma maneira de empregar a mão-de-obra. (Stroobants, 1993a, p. 276-277)

Dessa maneira, mesmo assumindo a perspectiva multidimensional de Zarifian, ou seja, mesmo assumindo que a noção de competência também comporta o lado do reconhecimento simbólico e monetário, acredita-se aqui que, do ponto de vista teórico, a qualificação é ainda mais ampla para abarcar os fenômenos não só do mercado de trabalho "formal" como também do mercado "informal" e do desemprego. Se Zarifian acredita que a definição da qualificação é limitada, é porque ele considera apenas a qualificação do trabalho ou do trabalhador, e não as relaciona, como faz Naville. Se seguimos a perspectiva navilleana, concluímos que é a qualificação que pode comportar 
Algumas reflexões sobre a qualificação do trabalho a partir...

tanto a dimensão individual - as competências dos indivíduos, suas qualidades - quanto a social - a maneira de qualificar essas qualidades, de reconhecer-lhes um valor. A definição das qualificações refere-se assim a um triplo desafio individual e coletivo, de aquisição de competências e de acesso aos empregos, de organização do trabalho e de evolução dos empregos, de status e de consideração social (Lichtenberger, s.d.).

Em contrapartida, mesmo que não se concorde com essa postura, há que se reconhecer, ao menos, que a qualificação não precisa ser substituída pela competência, já que, concebida de uma perspectiva mais ampla, seu conceito pode, sim, comportar os aspectos implícitos, informais e não organizados das características dos indivíduos. De resto, a palavra "qualificação" continua sendo utilizada, e até gramaticalmente ela parece ser mais abrangente do que a competência, já que, além de substantivo e adjetivo, ela pode ser também um verbo; e qualificar parece justamente dar conta dos processos sociais de hierarquização, do ato de classificar as diferentes capacidades de trabalho. De qualquer modo, o importante a notar é que, qualificação ou competência, o problema da qualidade do trabalho é, como bem mostrou Naville, multiplamente determinado, e sua medida em termos de qualificação contém arbitrários que não podem ser redutíveis a uma única medida e dimensão. $\mathrm{O}$ trabalho qualificado, em si, não possui, portanto, características próprias. Em uma palavra, a qualificação não pode ser derivada do tempo de formação e/ou da qualidade do trabalho, pois a concepção social de uma profissão, de uma função, é tão importante para sua classificação quanto seu conteúdo.

\section{Qualificação X competência: qual a pertinência do debate no Brasil?}

Essa defesa teórica do conceito de "qualificação" não significa, porém, que sua defesa política se possa fazer nos mesmos termos da sociedade francesa. Se assumimos que a qualificação é construída socialmente, isso implica conhecer a realidade na qual foi produzida. Dessa forma, antes de criticar a noção de "competência", a academia e os sindicatos no Brasil deveriam se perguntar pelo significado da apropriação de um discurso e de uma prática iniciadas em outro país. Do contrário, correm o risco de cair em um anacronismo.

Em primeiro lugar, é preciso atestar que a qualificação não teve aqui a centralidade adquirida nos países centrais, ou melhor, na França. Se, como bem mostrou Naville, a qualificação varia no tempo e 
no espaço, mesmo dentro do "modo de regulação fordista" ela possuía conotaçôes diferentes conforme o lugar: vimos que a existência de um sistema de qualificações codificado em uma grade de classificações profissionais que hierarquiza os indivíduos por meio dos postos de trabalho e no nível dos ramos profissionais é uma característica tipicamente francesa, o que, aliás, faz com que o conceito de "qualificação" tenha uma relevância que não se lhe dá para além das fronteiras da França (Saglio, 1998). Da mesma forma, isso também significa que o debate em torno da disputa política "qualificação(óes)" versus "competência(s)" parece ser muito particular a esse país. Em contrapartida, mesmo nos países onde não havia essa formalização em categorias - como na Alemanha e no Japão, onde sempre se classificaram os atributos gerais do indivíduo -, havia forte ênfase no mercado de trabalho interno, o que implicava uma carreira profissional previsível, ainda que desigual.

No Brasil, nunca tivemos essa estabilidade. Aqui, a relação diploma/cargo/salário nunca foi regulamentada e as classificaçóes profissionais não têm sentido empírico; o reconhecimento da qualificação sempre se deu de forma individual, pelo registro na carteira de trabalho, o que coloca o trabalhador nas mãos da empresa, já que "é ela quem decide se 'qualifica' ou não o funcionário, numa ação unilateral” (Kober, 2004, p. 122). Do ponto de vista da prática social, nós não tivemos lutas e processos sociais que concorressem para a codificação e avaliação das qualificações em termos de classificações e salários, tal como o sistema iniciado no pós-guerra na França. A maneira pela qual os trabalhadores franceses reivindicam a qualificação não tem nada a ver com a história do nosso país. Como então se pode contrapor à competência algo que não tivemos?

Além disso, no nível do discurso, a qualificação aportou entre nós, muito informada por essa literatura francesa do pós-guerra, especialmente pelo pensamento de Friedmann, que exerceu expressiva influência na "geração dos nossos pioneiros" - como Leôncio Martins Rodrigues e Juarez Brandão Lopes. Ainda que de forma secundária ou instrumental, a qualificação aparecia no estudo desses autores, muitas vezes como variável independente (qualificados $\mathrm{X}$ não qualificados) erguida para explicar atitudes e valores dos trabalhadores. Talvez pela influência friedmanniana, a reflexão sobre a temática parece ter privilegiado, aqui, a perspectiva que busca concluir por um aumento ou diminuição da qualificação com base nos conteúdos das tarefas e nas cor- 
Algumas reflexões sobre a qualificação do trabalho a partir...

respondentes características individuais para realizá-las, ou seja, esteve bastante próxima da perspectiva "substancialista", ainda que sem qualquer conhecimento disso.

De qualquer maneira, apesar dessa presença francesa nos primórdios da constituição da disciplina no país, sua contribuição teórica apaga-se completamente nas décadas seguintes. E hoje, apesar de seguir e se inspirar no debate contemporâneo francês sobre a disputa "qualificação(óes)" X "competência(s)" - no qual está fortemente presente a teorização de Friedmann e Naville -, a discussão acadêmica no Brasil praticamente desconhece a contribuição de ambos os autores. ${ }^{9}$ Mais ainda, Pedrosa (1995), comparando diversos estudos e pesquisas de autores brasileiros sobre a qualificação do trabalho, conclui que "mais significativo que as divergências sobre o sentido de qualificação é a própria indefinição do conceito: grande parte dos recentes estudos brasileiros não explicita o que 'qualificam' como qualificação" (p. 104).

Porém, se a qualificação e a competência têm aqui forte vigência simbólica e foram e são introduzidas nas relações de trabalho antes pelo debate acadêmico que pela própria vida cotidiana, é preciso conhecer teoricamente esse debate, e não apenas seus resultados políticos. Em outras palavras, a difusão e a vigência simbólicas da qualificação e da competência não podem ser confundidas com as práticas sociais de organização e controle do trabalho. De todo modo, reconhecer que o debate da realidade francesa não pode ser automaticamente transposto para cá não significa que ele não tenha sentido aqui, mas sim que deve ser recriado, em função de nossa especificidade histórica (natureza do mercado de trabalho, características da formação de uma classe operária nacional, força e poder de barganha dos sindicatos, formas e expressão material e simbólica das hierarquias sociais). $\mathrm{O}$ fato de não termos a referida contratação coletiva e homogeneização de salários, por exemplo, pode fazer com que a passagem da qualificação para a competência se torne aqui sinônimo de maior desregulamentação das relações de trabalho, deixando mais vulneráveis os trabalhadores.

Assim, em um contexto de forte desemprego, segmentação do mercado de trabalho e flexibilização dos vínculos empregatícios, tornase ainda mais importante recuperar a visão que afirma ser a qualificação construída socialmente, a fim de se observar as estratégias desenvolvidas pelas diferentes categorias de trabalhadores para inserir-se ou manter-se no mercado de trabalho. Se o diploma deixa de ser uma condi- 
ção suficiente para a inserção e manutenção nesse mercado e se, simultaneamente, as exigências nesse domínio e no âmbito das qualidades pessoais não cessam de aumentar, expressas na demanda por "polivalência", como explicar que essa tendência à maior "qualificação" não seja acompanhada, em muitos casos, de aumentos salariais? Mais ainda, se pessoas "qualificadas" não encontram lugar no mercado de trabalho, isso nada mais significa que elas estão "desqualificadas", já que "certas qualificações sem emprego (como é o caso de 'diplomados' que não encontram o gênero de trabalho ao qual o diploma parece permitir-lhes pretender) cessam de ser, então, socialmente, qualificações" (Naville, 1956, p. 130).

\section{Recebido e aprovado em julho de 2004.}

\section{Notas}

1. No Brasil, apesar de a qualificação ter entrado na pauta dos estudos sociológicos desde seus primórdios, ela não era o objeto central da análise. Da mesma forma, se a qualificação da força de trabalho esteve presente desde fins do século XIX/começo do XX, sendo institucionalizada com a fundação do SENAI em 1942, ela não pautava a discussão social, tal qual ocorreu na França.

2. É preciso ressaltar que essas reivindicações e suas posteriores conquistas diziam respeito basicamente aos trabalhadores brancos, assalariados, sindicalizados, do setor secundário da economia.

3. As lógicas que presidem os sistemas de classificação variam de país para país. A padronização das qualificações em uma grade de classificações profissionais objetiva e impessoal é uma característica tipicamente francesa e refere-se aos trabalhadores manuais, aos operários. Outros países, mesmo da Europa, não possuem essa formalização: "São as competências dos próprios assalariados que são classificadas (na Alemanha) e não os postos de trabalho ou as posiçōes hierárquicas (como na França)" (Maurice, apud Dubar, 1998b, p. 91). De qualquer forma, em todos eles "havia denominaçôes relativamente estáveis associadas a categorias de emprego que permitiam esperar uma progressão profissional desigual, mas previsível” (Dubar, 1998a, p. 70-71).

4. Deve-se enfatizar aqui que, em um processo de grandes mudanças como esse, não se pode afirmar a anterioridade de um fenômeno sobre outro, isto é, não se pode estabelecer uma relação causal e linear entre a crise do fordismo e as transformações tecnológicas, uma vez que fatores múltiplos concorreram para essa crise do capital e são por ela também afetados.

5. É preciso ressaltar que esses conteúdos de qualificação hoje requeridos não são tão "novos" assim. Em primeiro lugar, a "organização científica do trabalho" não elimina toda a iniciativa e a participação do trabalhador (Leite, 1994; Vargas, 1985) não só porque ele, sendo um ser vivo, não pode seguir apenas normas heterodeterminadas como também porque, mesmo não admitindo, o capital precisa do saber operário, de sua intervenção não planejada - a chamada "qualificação tácita" (Wood \& Jones, 1984) -, para fazer face aos

Educ. Soc., Campinas, vol. 25, n. 87, p. 353-382, maio/ago 2004

Disponível em <http://www.cedes.unicamp.br> 
Algumas reflexões sobre a qualificação do trabalho a partir...

imprevistos da produção. Em segundo lugar, essas características hoje consideradas inusitadas sempre foram típicas das indústrias de processo, mas, como estas não serviram de modelo para a teorização do fordismo, seus requisitos em termos de qualificação estiveram ocultados no imaginário acadêmico e gerencial.

6. Naville dedica uma parte do Essai... para afirmar que aquilo que ele considera "não-trabalho" também pode ser qualificado. Ou seja, não é apenas o trabalho profissional exercido para o ganho, o trabalho assalariado, enfim, o trabalho produtivo que pode ser mais ou menos qualificado, mas qualquer atividade humana. De um modo geral, as atividades que estão no topo da escala de qualidade são aquelas nas quais a qualidade do processo de trabalho se expressa juntamente com a qualidade da fruição prometida por seu objeto e se manifesta imediata e simultaneamente àquele que a exerce e àquele que é o espectador ou o usuário, ou seja, nas quais não há cisão entre produção e consumo: "São as atividades exteriores ao trabalho propriamente dito que extraem todo seu preço dessa propriedade qualitativa, em particular aquelas que derivam das manifestaçóes da cultura" (Naville, 1956, p. 15). Todavia, no salariado, essas atividades caem, em algum momento, no domínio da avaliação econômica, isto é, da produção e da formação de lucros e, como tal, têm suas qualidades "como que obscurecidas pelas condições econômicas de sua manifestação" (idem, ibid., p. 16).

7. A classificação de Friedmann e Naville nas perspectivas "substancialista" versus "relativista" não pode ser reificada: em primeiro lugar, porque o pensamento de Friedmann não é tão simplista como pode parecer à primeira vista, dadas as diversas mediaçôes nele presentes. É assim que, apesar de derivar a qualificação da complexidade do trabalho e do grau de inteligência necessário para realizá-lo, ele acaba relativizando o tempo de formação como critério da qualificação. Naville, em contrapartida, apesar de enfatizar a todo momento a relatividade da qualificação, acaba tomando o tempo de formação como elemento essencial para medi-la. Apesar de não termos detalhado essas nuanças, acreditamos que a denominação "substancialista" e "relativista" a ambos os autores é, sim, pertinente, mas pertinente para mostrá-los como fundadores das posturas que se seguiriam depois, concretizadas na constituição de duas equipes separadas, no final da década de 1960 - equipes que permanecem até hoje, no Laboratoire Georges Friedmann e no Laboratoire Pierre Naville (Dadoy, 1987).

8. Enjeu é um termo francês que não possui uma tradução exata e fiel em português. Aproximadamente, podemos dizer que significa "o que está em jogo", "desafio".

9. É preciso reconhecer que, depois das contribuiçôes da ergonomia, dos estudos sobre qualificações tácitas e sobre gênero, e da influência das críticas aos teóricos do processo de trabalho, a literatura brasileira passou a conceituá-la, e de uma maneira que a aproximava da concepção "relativista". Porém, apesar de ser o precursor desta visão - que já é, hoje, quase um truísmo -, Naville é raramente mencionado no país.

\section{Referências bibliográficas}

\section{ALALUF, M. Le temps du labeur. Bruxelles: Université de Bruxelles, 1986.}
ALALUF, M. Le travail ne suffit pas à qualifier l'ouvrier. In: Cours-SALIES, P. (Coord.). La liberté du travail. Paris: Syllepse, 1995. p. 151-163.

CADRES. Définir la qualification? CADRES, n. 313, p. 46-49, juin 1984. 
CAMPINOS-DUBERNET, M.; MARRY, C. De l'utilisation d'un concept empirique: la qualification; quel rapport à la formation?. In: TAnguY, L. (Dir.). L'introuvable relation formation/emploi: un état de recherches en France. Paris: La Dócumentation Française, 1986. p. 197-232.

CARDI, F. L'orientation professionnel et la qualification. In: BURNIER, M.; Célérier, S.; Spurk, J. (Dir.). Des sociologues face à Pierre Naville ou l'archipel des savoirs. Paris: L'Harmattan, 1997. p. 103-108.

CORIAT, B. La régulation dans la crise actuelle. Les Cahiers Français, n. 209, p. 65-68, jan./fev. 1983.

CORIAT, B. L'atelier et le chronomètre. 3. éd. Paris: Christian Bourgois, 1994.

DADOY, M. Qualification et structures sociales. CADRES, n. 313, p. 5483, juin 1984.

DADOY, M. La notion de qualification chez Georges Friedmann. Sociologie du Travail, Paris, v.29, n. 1, p. 15-34, jan./mar. 1987.

DADOY, M. Analyse du travail e classifications professionnelles. In: DADOY, M. et al. (Dir.). Les analyses du travail: enjeux et formes. Paris: CNRS, 1990. (Collection des études, n. 54) (mimeo)

DUBAR, C. Les identités professionnelles. In: Kergoat, J. et al. (Dir.). Le monde du travail. Paris: La Découverte, 1998a. p. 66-74.

DUBAR, C. A sociologia do trabalho frente à qualificação e à competência. Educação \& Sociedade. Campinas, v. 19, n. 64, p. 87-103, set. 1998b. Número especial.

DUBAR, C.; TRIPIER, P. Sociologie des professions. Paris: A. Colin, 1998.

ERBÈS-SEGUIN, S. La sociologie du travail. Paris: La Découverte, 1999.

EYRAUD, F. Comparacion internacional de los sistemas de clasificacion. In: Jobert, A. et al. Formación profesional: calificaciones y clasificaciones profesionales; su influencia en las relaciones de trabajo; la experiencia francesa. Buenos Aires: Piette; Humanitas, 1992. p. 15-26. 
Algumas reflexões sobre a qualificação do trabalho a partir...

FRIEDMANN, G. Problèmes humains du machinisme industriel. Paris: Galimard, 1946.

FRIEDMANN, G. Où va le travail humain?. 11. éd. Paris: Gallimard, 1950 .

FRIEDMANN, G. Le travail en mièttes: spécialisation et loisirs. Paris: Gallimard, 1956.

FRIEDMANN, G. Sept études sur l'homme et la technique. Paris: Ghontier, 1977.

FRIEDMANN, G.; NAVILLE, P. Prefácio. In: Friedmann, G.; NaVille, P. (Org.). Tratado de sociologia do trabalho. São Paulo: Cultrix, 1973. v.2, p. $13-15$.

HARVEY, D. Condição pós-moderna. São Paulo: Loyola, 1996.

HIRATA, H. Da polarização das qualificações ao modelo de competência. In: Ferretti, C.J.; Zibas, D.M.; Madeira, F.R. et al. (Org.). Novas tecnologias, trabalho e educação: um debate multidisciplinar. 3. ed. Petrópolis: Vozes, 1996. p. 128-142.

JOBERT, A. Las grillas de clasificacion profesional: algunas referencias historicas. In: JoberT, A. et al. Formación profesional: calificaciones y clasificaciones profesionales; su influencia en las relaciones de trabajo; la experiencia francesa. Buenos Aires: Piette; Humanitas, 1992. p. 1-13.

KOBER, C.M. Qualificação profissional, uma tarefa de Sísifo. Campinas:. Autores Associados, 2004.

LEITE, M. de P. O futuro do trabalho: novas tecnologias e subjetividade operárias. São Paulo: Scritta, 1994.

LICHTENBERGER, Y. La calificacion; apuesta social, desafio productivo. In: JoberT, A. et al. Formación profesional: calificaciones y clasificaciones profesionales; su influencia en las relaciones de trabajo; la experiencia francesa. Buenos Aires: Piette; Humanitas, 1992. p. $27-41$.

MACHADO, L.R. de S. O "modelo de competências" e a regulamentação da base curricular nacional e de organização do ensino médio. Trabalho \& Educação, Belo Horizonte, n. 4, p. 79-95, ago./dez. 1998. 
NAVILLE, P. Essai sur la qualification du travail. Paris: Rivière, 1956. p. $135-1$

NAVILLE, P. Vers l'automatisme social?: problèmes du travail e de l'automation. Paris: Gallimard, 1963.

NEFFA, J.C. Clasificaciones e calificaciones profesionales: un nuevo e apasionante campo para la investigación desde la perspectiva de las ciencias sociales del trabajo. In: JOBERT, A. et al. Formación profesional: calificaciones y clasificaciones profesionales; su influencia en las relaciones de trabajo; la experiencia francesa. Buenos Aires: Piette; Humanitas, 1992. p. I-XXI.

PAIVA, V. Produção e qualificação para o trabalho: uma revisão da bibliografia internacional. Rio de Janeiro: Instituto de Economia Industrial, 1989. 72p. (mimeo)

PAIVA, V. Inovação tecnológica e qualificação. Educação \& Sociedade, Campinas, v. 16, n. 50, p. 70-92, abr. 1995.

PEDROSA, J.G. Análise comparativa das abordagens sobre qualificação e transformaçôes no trabalho. 1995. Dissertação (Mestrado) - Faculdade de Educação, Universidade Federal de Minas Gerais, Belo Horizonte.

ROPÉ, F.; TANGUY, L. Introdução. In: Ropé, F.; TANGUY, L. (Org.). Saberes e competências: o uso de tais noções na escola e na empresa. Campinas: Papirus, 1997. p. 15-24.

SAGLIO, J. Qualification et classification. In: Kergoat, J. et al. (Dir.). Le monde du travail. Paris: La Découverte, 1998. p. 257-264.

STROOBANTS, M. La compétence à l'épreuve de la qualification. In: Durand, J.P. (Dir.). Vers un nouveau modèle productif? Paris: Syros; Alternatives, 1993a. p. 267-284

STROOBANTS, M. Savoir-faire e compétence au travail: une sociologie de fabrication des aptitudes. Bruxelles: Université de Bruxelles, 1993 b.

STROOBANTS, M. A visibilidade das competências. In: Ropé, F.; TANGuY, L. (Org.). Saberes e competências: o uso de tais noçôes na escola e na empresa. Campinas: Papirus, 1997. p. 135-166. 
Algumas reflexões sobre a qualificação do trabalho a partir...

TANGUY, L. Pierre Naville, 1942-1960: une sociologie des relations. In: Éliard, M. (Dir.). Naville, la passion de la connaissance. Toulouse: Presses Universitaires de Mirail, 1996. p. 55-67.

TANGUY, L. Competências e integração social na empresa. In: Ropé, F.; TAnguY, L. (Org.). Saberes e competências: o uso de tais noções na escola e na empresa. Campinas: Papirus, 1997a. p. 167-199.

TANGUY, L. Formação: uma atividade em vias de definição?. Veritas, Porto Alegre, v. 42, n. 2, p. 385-410, jun. 1997 b.

TANGUY, L. Pierre Naville: introduction; du psychologue au sociologue, un homme de science dérangeant. Orientation Scolaire et Professionnelle, Paris, v. 26, n. 2, p. 171-182, avr./juin 1997c.

TARTUCE, G.L.B.P O que há de novo no debate da "qualificação do trabalho"?: reflexôes sobre o conceito com base nas obras de Georges Friedmann e Pierre Naville. 2002. Dissertação (Mestrado) - Faculdade de Filosofia, Letras e Ciências Humanas, Universidade de São Paulo, São Paulo.

VARGAS, N. Gênese e difusão do taylorismo no Brasil. Ciências Sociais Hoje, São Paulo, p. 155-189, 1985.

WOOD, S.; JONES, B. Qualifications tacites, division du travail et nouvelles technologies. Sociologie du Travail, Paris, v. 26, n. 4, p. 407-421, oct./dec. 1984.

ZARIFIAN, P. Compétences et organisation qualifiante en milieu industriel. In: Minet, F.; PARlier, M.; Witt, S. (Dir.). La compétence: mythe, construction ou realité? Paris: L'Harmattan, 1994. p. 111-133.

ZARIFIAN, P. Sur le modèle de la compétence; intervention orale à l'École Polytechnique, São Paulo, 23 août 1995. (mimeo)

ZARIFIAN, P. A competência e os modelos produtivos. Notas sobre a palestra proferida no 21. Congreso de la Asociación Latinoamericana de Sociología, São Paulo, ago./set. 1997. (mimeo)

ZARIFIAN, P. A gestão da e pela competência. In: SEMINÁRIO INTERNACIONAL EDUCAÇÃO PROFISSIONAL, TRABALHO E COMPETÊNCIAS, 1996, Rio de Janeiro. Anais... Rio de Janeiro: SENAI, 1998. p. 15-24. 